\title{
量子点敏化太阳能电池研究进展
}

\author{
卫会云王国帅吴会觉罗艳红 李冬梅* 孟庆波 ${ }^{*}$ \\ (中国科学院物理研究所, 中科院清洁能源前沿研究重点实验室, 北京市新能源材料与器件重点实验室, 北京 100190)
}

\begin{abstract}
摘要：量子点敏化太阳能电池(QDSCs)因其制备成本低、工艺简单及量子点(QDs)本身的优异性能(如尺寸效 应、多激子效应)等优点, 近年来受到广泛关注。在此类电池中, 无机半导体量子点敏化剂作为吸光材料, 其自身的光电性质、制备方法、表面缺陷、化学稳定性及其在 $\mathrm{TiO}_{2}$ 光阳极上的敏化方法等是影响电池性能的 关键。本文综述了无机半导体量子点敏化剂(包括窄带隙二元量子点、多元合金量子点及Type-II核壳量子点) 的最新研究进展, 重点介绍了胶体量子点的制备方法; 分类阐释了量子点在 $\mathrm{TiO}_{2}$ 光阳极表面的沉积与敏化方 法, 特别是双官能团辅助自组装吸附法; 总结了针对提高电子注入效率和减少复合的量子点表面修饰方法; 最后简要介绍了QDSCs的电解质和对电极的研究进展。
\end{abstract}

关键词: 量子点敏化太阳能电池; 无机半导体量子点; 胶体量子点; 双官能团辅助自组装; 表面修饰 中图分类号: 0649

\section{Progress in Quantum Dot-Sensitized Solar Cells}

\author{
WEI Hui-Yun WANG Guo-Shuai WU Hui-Jue LUO Yan-Hong \\ LI Dong-Mei* MENG Qing-Bo*
}

(Beijing Key Laboratory for New Energy Materials and Devices, Key Laboratory for Renewable Energy, Chinese Academy of Sciences, Institute of Physics, Chinese Academy of Sciences, Beijing 100190, P. R. China)

\begin{abstract}
Quantum dot-sensitized solar cells (QDSCs) have attracted much attention in the past few years because of the advantages of quantum dots (QDs), including low cost, easy fabrication, size-dependence bandgap, and multiple exciton generation (MEG). The properties of QD sensitizers influence the performance of QDSCs, such as their photoelectric characteristics, preparation methods, surface defects, chemical stability, and their sensitization towards $\mathrm{TiO}_{2}$ photoanodes. This review demonstrates the development of QD sensitizers, including narrow bandgap binary QDs, ternary or quaternary alloyed QDs, and Type-II core-shell QDs, especially the preparation methods of colloidal QDs. Furthermore, the deposition and sensitization methods of QDs are introduced in detail, particularly bifunctional-assisted self-assembly deposition. Meanwhile, methods to improve electron injection efficiency and reduce charge recombination are also summarized. Finally, a brief introduction is provided to the development of electrolytes and counter electrodes in QDSCs.
\end{abstract}

Key Words: Quantum dot-sensitized solar cell; Inorganic semiconductor quantum dot;

Colloidal quantum dot; Bifunctional-assisted self assembly; Surface treatment

Received: October 24, 2015; Revised: December 3, 2015; Published on Web: December 3, 2015.

"Corresponding authors. LI Dong-Mei, Email: dmli@iphy.ac.cn. MENG Qing-Bo, Email: qbmeng@iphy.ac.cn.

The project was supported by the National Natural Science Foundation of China $(91433205,51402348,51421002,21173260,11474333,91233202)$

and National Key Basic Research Program of China (973) (2012CB932903).

国家自然科学基金 $(91433205,51402348,51421002,21173260,11474333,91233202)$ 和国家重点基础研究发展规划项目(973)

(2012CB932903)资助

CEditorial office of Acta Physico-Chimica Sinica 


\section{1 引 言}

太阳能电池是一种利用光伏效应或光化学效 应将太阳能转化为电能的能量转换形式。按照其 发展历程, 太阳能电池可以分为三类: 以单晶硅 太阳能电池为代表的第一代太阳能电池, 这类电 池发展最为成熟, 最高光电转换效率已达 $25 \%$, 且 稳定性好, 在市场上占据着主导地位, 但是高纯 度的单晶硅价格昂贵，较高的生产成本使其目前 仍难以和传统能源相竞争; 以铜铟镓硒(CIGS)和碲 化镉 $(\mathrm{CdTe})$ 薄膜太阳能电池等为代表的第二代太阳 能电池, 采用高消光系数、直接带隙吸光材料可 以有效降低电池的制造成本, 光电转换效率可达 $20 \%$ 以上，但受到环境污染和稀有元素In储量低的 限制; 此外, 以铜锌锡硫(CZTS)太阳能电池、染 料敏化太阳能电池、钙钛矿型太阳能电池和量子 点太阳能电池等低成本、高效率新型太阳能电池 为代表的第三代太阳能电池正在快速发展。无机 半导体量子点消光系数高、合成过程简单, 并且 其独特的量子限域效应、热电子抽取以及多激子 效应(MEG)等优点使得基于量子点的光伏器件(即 量子点太阳能电池)理论光电转化效率高达 $44 \%$, 突破Shockley-Queisser极限(31\%) $)^{1-3}$ 。

量子点太阳能电池主要包括肖特基量子点太 阳能电池、耗尽异质结太阳能电池、有机-无机杂 化太阳能电池以及量子点敏化太阳能电池 $(\mathrm{QDSCs})^{48}$, 本文主要介绍量子点敏化太阳能电池 方面的工作。QDSCs 是在染料敏化太阳能电池 (DSCs) 的基础上发展而来的, 它采用无机窄带隙 的半导体量子点 $(\mathrm{QDs})$ 作为敏化剂, 克服了传统的 钉-联吡啶染料和有机染料吸光范围较窄的缺点, 并且电池的制备成本更低。事实上, 在上世纪 80 年代初, 人们就提出了量子点敏化宽禁带半导 体的概念。1994年, Weller等 ${ }^{9}$ 以 PbS、CdS 量子点 等敏化 $\mathrm{TiO}_{2}$ 多孔膜为工作电极, 建立了三电极电池 体系, 并研究了其电流-电压特性。但是, 这种量 子点敏化电池的研究在相当长一段时间内发展缓 慢, 光电转化效率低。近几年, 随着量子点材料 制备方法和薄膜沉积工艺的不断改进，人们对电 池内部机理研究的不断深入, QDSCs 效率有了大 幅提升, 成为新型太阳能电池领域一个新研究热 点。

尽管QDSCs理论效率高, 但目前其光电转换 效率只有约 $8 \%$ 左右 ${ }^{10-12}$, 远低于 DSCs $(\text { 约 } 13 \%)^{13}$, 因
此, 进一步提高QDSCs 性能仍需面临很多挑战。 影响电池性能的主要因素包括: QDs本身的光电特 性、金属氧化物光阳极的结构和形貌、电解质中 氧化还原电对的氧化还原电位及载流子迁移率、 对电极的催化性能及电池结构等, 其中量子点及 其在光阳极表面的敏化是影响整个电池性能的关 键。本文主要综述了量子点敏化剂(包括窄带隙二 元量子点、多元合金量子点以及Type-II核壳量子 点)最新研究进展, 重点介绍了胶体量子点的合成 方法; 分类阐释了量子点在 $\mathrm{TiO}_{2}$ 光阳极表面的沉积 与敏化方法, 特别是双官能团辅助自组装吸附方 法; 总结了针对有效提高电子注入效率和减少复 合的量子点表面修饰方法; 最后简要介绍了 QDSCs 其他组成部分 (金属氧化物光阳极、电解质 和对电极)的研究进展。

\section{QDSCs的组成及工作原理}

QDSCs由沉积了量子点的光阳极、电解质和 对电极三部分组成，其工作原理与DSCs相似。如 图1所示，光照下，量子点吸收光子后被激发，产 生电子-空穴对并发生分离，电子快速注入到 $\mathrm{TiO}_{2}$ 导带并经 $\mathrm{TiO}_{2}$ 被外电路收集，量子点的空穴被 电解质还原回到基态，电解质在对电极处接收外 电路流入的电子完成再生，从而完成一个循环。 光电转换主要通过三个界面完成: (1) 量子点与金 属氧化物半导体界面; (2) 量子点和电解质界面和 (3)电解质与对电极界面。具体而言, 光阳极是由 具有介孔结构的宽禁带半导体氧化物 $\left(\mathrm{TiO}_{2}\right.$, $\mathrm{SnO}_{2}, \mathrm{ZnO}$ )薄膜及沉积在薄膜上的量子点构成;

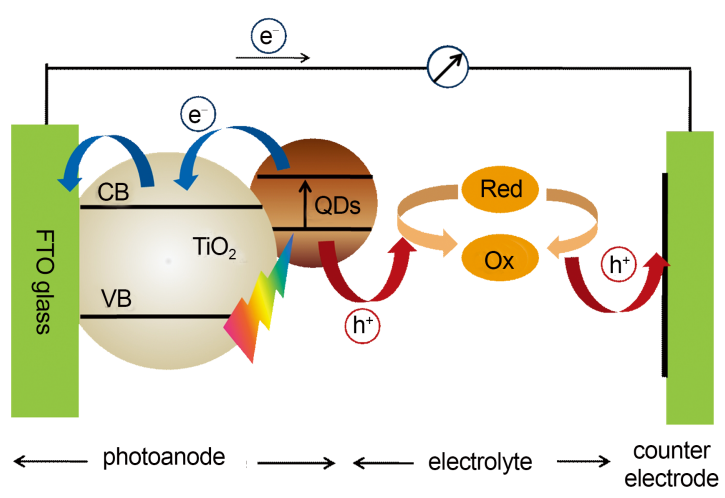

图1 量子点敏化太阳能电池(QDSC)结构及工作原理图

Fig.1 Structure and working mechanism for the quantum dot-sensitized solar cell (QDSC)

FTO: fluorinated tin oxide; VB: valence band; CB: conduction band; Ox: oxidized species; Red: reduced species 
电解质主要是用来还原、再生量子点, 目前最常 用的电解质为含有多硫氧化还原电对 $\left(\mathrm{S}^{2-} / \mathrm{S}_{x}^{2-}\right)$ 的水 溶液, 也有少量报道采用 $\mathrm{I}^{-} / \mathrm{I}_{3}^{-} 、 \mathrm{Co}^{2+} / \mathrm{Co}^{3+}$ 等非硫氧 化还原电对; 对电极主要起到还原电解质中氧化 型物种的作用，对电极材料目前主要包括贵金 属、碳材料和金属硫化物三类。

\section{3 光阳极的研究进展}

QDSCs 的光阳极是指经量子点敏化的具有多 孔结构的宽禁带半导体氧化物薄膜。对于 QDSCs来讲, 电池性能与量子点对光阳极的敏化 方法密切相关。人们发展了多种量子点敏化 $\mathrm{TiO}_{2}$ 或 其它宽禁带半导体薄膜的方法, 主要包括三大 类: (1) 原位化学沉积法, 包括化学浴沉积法 (CBD) 和连续离子层吸附与反应法(SILAR); (2)先 合成量子点胶体, 再直接或借助带有双官能基团 的有机小分子将量子点针定在电极表面; (3)其它 的沉积方法, 如电化学沉积法、化学气相沉积法 (CVD) 等, 我们将结合不同量子点的合成方法及量 子点在光阳极的沉积方法一并介绍。

\section{1 量子点敏化剂}

量子点敏化剂是QDSCs光吸收的核心, 电池 的光捕获、电荷分离及传输过程都与量子点自身 的性质相关, 是决定电池性能的关键材料之一。 理想的量子点敏化剂应该具有光吸收范围宽、合 适的导带位置以及表面缺陷少等特点。对于整个 电池体系而言, 能级匹配非常重要, 量子点的导 带必须高于半导体氧化物的导带, 这样才能实现 电子的快速抽取。目前, 常用的量子点包括 $\mathrm{CdS}$ 、 $\mathrm{CdSe} 、 \mathrm{PbS} 、 \mathrm{CdTe} 、 \mathrm{Sb}_{2} \mathrm{~S}_{3} 、 \mathrm{CuInS}_{2}$ 等。

\subsubsection{CdS/CdSe量子点共敏化}

$\mathrm{CdS} 、 \mathrm{CdSe}$ 量子点与 $\mathrm{TiO}_{2}$ 能级匹配, 在电解质 中有很好的稳定性, 且沉积工艺成熟, 因而被广 泛用于QDSCs中。由于 $\mathrm{CdS}$ 的带隙较宽 $(2.4 \mathrm{eV})$, 吸光范围窄, 而 $\mathrm{CdSe}$ 的吸收带边虽然可以拓展到 $700 \mathrm{~nm}$, 但电子注入效率较低, 因此, 通常采用 $\mathrm{CdS} / \mathrm{CdSe}$ 量子点共敏化的方式, 不仅能提高光的 捕获效率，同时也提高了电子的注入效率。 $\mathrm{CdS} / \mathrm{CdSe}$ 量子点对 $\mathrm{TiO}_{2}$ 多孔膜的敏化主要采取原 位沉积方法。Toyoda等 ${ }^{14-17}$ 研究了 $\mathrm{TiO}_{2}$ 光阳极形貌 对QDSCs性能的影响, 他们在具有三维有序反蛋 白石结构的 $\mathrm{TiO}_{2}$ 光阳极上原位沉积了 $\mathrm{CdS} / \mathrm{CdSe}$ 量
子点, 获得了 $3.5 \%$ 的转换效率。孟庆波等 ${ }^{18}$ 通过优 化多孔光阳极的结构及量子点沉积条件, 使 $\mathrm{CdS} / \mathrm{CdSe}$ QDSCs 效率达到 $4.92 \%$ 。 Lee等 ${ }^{19}$ 系统研 究了 $\mathrm{CdS}$ 和CdSe的沉积顺序对共敏化QDSCs性能的 影响。随着电池结构和制备工艺的不断改进, 基 于 $\mathrm{CdS} / \mathrm{CdSe}$ 的QDSCs 研究取得了很大进展, 电池 效率也不断提高。Kuang 等 ${ }^{20}$ 发展了一种新的 $\mathrm{TiO}_{2}$ 光阳极结构, 有效改善了量子点的负载和电子的 传输, 使 $\mathrm{CdS} / \mathrm{CdSe}$ QDSCs的转换效率突破 $6 \%$ 。 Wang 等 ${ }^{2}$ 将 $\mathrm{Cu}_{2-x} \mathrm{Se}$ 对电极用于 $\mathrm{CdS} / \mathrm{CdSe}$ QDSCs, 通过电化学阻抗谱分析得到 $\mathrm{Cu}_{2-x} \mathrm{Se}$ 对电极的载流子 转移阻抗 $(0.58 \Omega)$ 远小于常用的 $\mathrm{Cu}_{2} \mathrm{~S}$ 对电极 (1.48 $\Omega)$, 说明 $\mathrm{Cu}_{2-\mathrm{x}} \mathrm{Se}$ 在还原 $\mathrm{Sn}^{2-}$ 的过程中展现出更高的 催化活性, 从而使电池获得更高的短路电流和开 路电压; 此外, 他们用 $\mathrm{TiO}_{2}$ 纳米片和纳米颗粒混合 物取代商品WER2-O Dyesol 浆料(颗粒尺寸约 150-250 nm)来制备光阳极的散射层, 其更大的比 表面积增加了量子点的负载量, 使电池获得高达 $20.83 \mathrm{~mA} \cdot \mathrm{cm}^{-2}$ 的电流和 $7.11 \%$ 的高效率, 这也是目 前液结 $\mathrm{CdS} / \mathrm{CdSe}$ QDSCs的最高效率。此外, 钟新 华等 ${ }^{2}$ 采用有机相高温热注入法制备了具有反转 Type-I能带排列的 CdS/CdSe核壳结构量子点, 电池 效率达到 $5.32 \%$ 。

尽管 CdS/CdSe QDSCs效率已经突破7\%, 但由 于其吸光范围有限, 电池效率提升空间不大。因 此, 进一步拓宽量子点的吸收范围并实现量子点 在金属氧化物光阳极上的高负载量是获得高效率 电池的发展方向。

\section{1 .2 窄带隙的二元量子点}

$\mathrm{PbS}$ 和 $\mathrm{PbSe}$ 是IV-VI族半导体化合物, 具有较 窄的带隙 $(\mathrm{PbS}$ 和 $\mathrm{PbSe}$ 带隙分别为 0.41 和 $0.28 \mathrm{eV})$ 和 较大的波尔半径 $(\mathrm{PbS}$ 和 $\mathrm{PbSe}$ 分别为 18 和 $46 \mathrm{~nm})$, 因 此, 在太阳能电池中具有潜在的应用。PbS有高达 (1-5) $\times 10^{5} \mathrm{~cm}^{-1}$ 的吸收系数, 并且因其较大的波尔 激子半径使得 $\mathrm{PbS}$ 带隙可以在较大范围内调节, 吸 光范围可拓宽至近红外区。2010年Parkinson等 ${ }^{23}$ 从 实验上观测到了 $\mathrm{PbS}$ 量子点敏化 $\mathrm{TiO}_{2}$ 体系的多激子 效应, 其内量子效率大于 $100 \%$ (如图2(a)所示)。 $\mathrm{PbSe}$ 胶体量子点由于其高度的量子限制效应以及 多激子效应被成功用于固态量子点太阳能电池 中, 获得6.2\% 的电池效率 ${ }^{24}$ 。2011年, Nozik等 25 进 一步观测到 $\mathrm{PbSe}$ 量子点电池体系的多激子效应, 

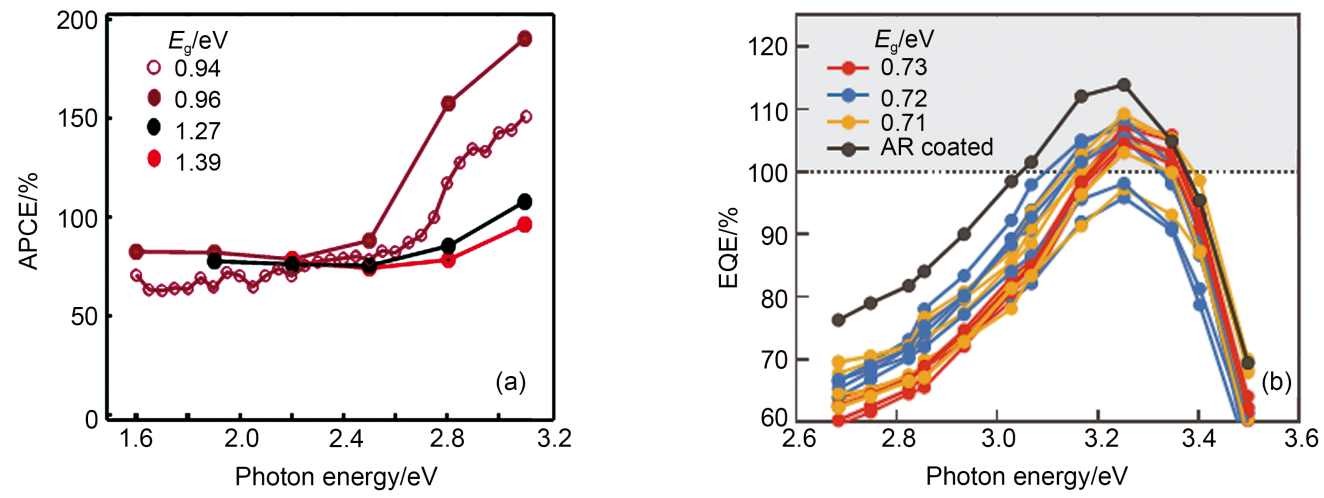

图2 (a)不同尺寸PbS量子点电池的内量子效率 $(\mathrm{APCE})$ 曲线 ${ }^{23}$; (b) 基于不同带隙 $\left(E_{\mathrm{g}}\right) \mathrm{PbSe}$ 量子点的电池及减反射 $\mathrm{AR}$ 膜的外 量子效率 $\mathrm{EQE}$ 曲线

Fig.2 (a) Absorbed photon-to-current efficiency (APCE) curves of PbS QDs with different $\operatorname{sizes}^{23}$; (b) external quantum efficiency (EQE) peaks for the devices made with various QD bandgaps $\left(E_{\mathrm{g}}\right)$, as well as a device with an antireflective (AR) coating ${ }^{25}$

外量子效率超过 $100 \%$; 最好器件的外量子效率为 $(107.5 \pm 0.6) \%$, 采用 $70 \mathrm{~nm}$ 厚 $\mathrm{MgF}_{2}$ 作为减反膜，外 量子效率提高到 $(114 \pm 1) \%($ 图2(b))。

基于 $\mathrm{PbS}$ 胶体量子点的肖特基太阳能电池的光 电流超过 $21 \mathrm{~mA} \cdot \mathrm{cm}^{-2}$, 说明 $\mathrm{PbS}$ 是一种具有很大潜 力的光吸收材料 ${ }^{26}$ 。目前, 已经有很多基于 $\mathrm{PbS}$ 量 子点QDSCs的报道。Mora-Seró等 27,28 在 $\mathrm{PbS}$ 表面包 覆 $\mathrm{CdS}$, 有效解决了 $\mathrm{PbS}$ 与多硫电解质接触时的不 稳定问题, 并通过优化原位沉积 $\mathrm{PbS}$ 的前驱物, 获 得高达 $22 \mathrm{~mA} \cdot \mathrm{cm}^{-2}$ 的短路电流和 $4.20 \%$ 的效率。孟 庆波等 ${ }^{29}$ 将一种分等级结构 $\mathrm{TiO}_{2}$ 光阳极用于 $\mathrm{PbS}$ QDSC中，获得了 $18.8 \mathrm{~mA} \cdot \mathrm{cm}^{-2}$ 的电流和 $3.82 \%$ 的 效率; 由于 $\mathrm{PbS} / \mathrm{CdS}$ 量子点的吸光范围可以达到 $1100 \mathrm{~nm}$, 而 $\mathrm{CdS} / \mathrm{CdSe}$ 量子点在可见光范围内有很 强的吸收, 因此, 基于铜网对电极, 进一步设计 叠层量子点太阳能电池(上层: $\mathrm{CdS} / \mathrm{CdSe}$ QDSCs,

下层： $\mathrm{PbS} / \mathrm{CdS}$ QDSCs), 获得了全光谱太阳能电 池, 短路电流达到 $25.12 \mathrm{~mA} \cdot \mathrm{cm}^{-2}$, 电池效率为 $5.06 \%{ }^{30}$ 。 $\mathrm{Park}$ 等 ${ }^{31}$ 通过在 $\mathrm{PbS}$ 量子点晶格间隙引入 $\mathrm{Hg}^{2+}$, 增强了 $\mathrm{Pb}-\mathrm{S}$ 键, 改善了 $\mathrm{Pb}^{2+}$ 周围的有序性和 共价性，从而加快了电子注入，抑制了复合，获 得了高达 $30 \mathrm{~mA} \cdot \mathrm{cm}^{-2}$ 的短路电流。

尽管 $\mathrm{PbS}$ 和 $\mathrm{PbSe}$ 作为光吸收材料可以将 QDSCs的光吸收范围扩展至近红外区, 提高了电 池的光电流，但同时引入了严重的复合，并且电 池的稳定性也存在问题。为了解决 $\mathrm{PbSe}$ 长期暴露 在空气中的不稳定性问题, 人们通过在 $\mathrm{PbSe}$ 表面 包覆 $\mathrm{PbCl}_{2}$ 层或通过阳离子交换的办法在 $\mathrm{PbSe}$ 表面
引入 $\mathrm{CdSe}$ 层来钝化 $\mathrm{PbSe}$ 量子点, 有效提高了量子 点的稳定性 32 。 $\mathrm{PbS}$ 量子点本身较慢的电子转移机 制导致较低的载流子分离和收集效率。根据文献 报道, 电子从 $\mathrm{PbS}$ 量子点导带注入到 $\mathrm{TiO}_{2}$ 导带的速 率仅为 $\mathrm{CdSe}$ 注入速率的 $1 / 5^{33}$, 因此, 发展表界面 处理技术以改善 $\mathrm{PbS}$ 量子点的电子注入和抑制复 合，实现载流子的有效分离和高效收集是基于 $\mathrm{PbS}$ 量子点的QDSCs的发展方向。

\subsection{3 多元合金量子点}

在QDSCs发展之初, 主要采用组成单一的二 元量子点, 如 $\mathrm{CdSe} 、 \mathrm{CdS} 、 \mathrm{PbS} 、 \mathrm{PbSe} 、 \mathrm{InAs}$ 等 ${ }^{34}$, 但基于这些量子点的电池效率普遍偏低。 近年来, 随着量子点合成工艺的发展与不断改 进, 高质量的 $\mathrm{CuInS} 、 \mathrm{CuInSe}$ 、 $\mathrm{CdSe}_{x} \mathrm{Te}_{1-x}$ 、 $\mathrm{CuInSe}_{x} \mathrm{~S}_{2-x} 、 \mathrm{Cu}_{2} \mathrm{ZnSnS}_{4} 、 \mathrm{CuInTe}_{2} 、 \mathrm{CuInTe}_{2-x} \mathrm{Se}_{x}$ 等 多元合金量子点被成功制备 ${ }^{38-42}$, 这些多元合金量 子点的吸光范围比相应的二元量子点更宽。钟新 华等 ${ }^{43}$ 采用有机高温热注入的方法, 并利用阴离子 合金的 “光曲效应” 得到了 $\mathrm{CdSe}_{x} \mathrm{Te}_{1-x}$ 合金量子点, 如图3所示, 其吸收带边达到 $800 \mathrm{~nm}$, 远大于与 $\mathrm{CdSe}_{x} \mathrm{Te}_{1-x}$ 粒径相同的 $\mathrm{CdSe}(614 \mathrm{~nm})$ 和 $\mathrm{CdTe}$ 的吸收 边 $(680 \mathrm{~nm})$, 并且 $\mathrm{CdSe}_{x} \mathrm{Te}_{1-x}$ 合金量子点的化学稳定 性比 $\mathrm{CdSe}$ 和 $\mathrm{CdTe}$ 更高, 再借助带有双官能基团的 有机小分子将量子点针定在电极表面。孟庆波等 ${ }^{44}$ 采用微波辅助合成方法水体系中制备了 $\mathrm{CdSe}_{x} \mathrm{Te}_{1-x}$ 量子点, 并将其用于QDSCs中。

$\mathrm{CuInS}_{2}$ 是一种直接带隙的半导体材料, 体相带 隙为 $1.5 \mathrm{eV}$, 具有高的消光系数, 更重要的是, 

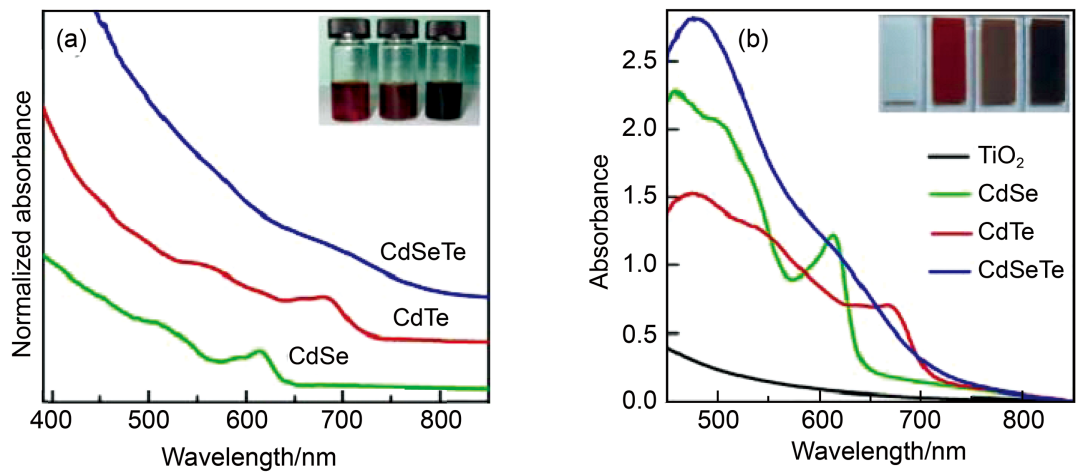

图3 CdSeTe, $\mathrm{CdTe}$ 和 $\mathrm{CdSe}$ 量子点在溶液(a)及敏化 $\mathrm{TiO}_{2}$ 膜(b)的吸收谱 ${ }^{43}$

Fig.3 Absorption spectra of CdSeTe, CdTe, and CdSe QDs in both (a) solution and (b) sensitized $\mathrm{TiO}_{2}$ film $^{43}$

Insets are photographs of CdSeTe, $\mathrm{CdTe}$, and CdSe QDs from right to left (a) in solution and (b) deposited on $\mathrm{TiO}_{2}$ films.

$\mathrm{CuInS}_{2}$ 材料绿色环保。赵家龙等 45 研究发现 $\mathrm{CuInS}_{2}$ 量子点到 $\mathrm{TiO}_{2}$ 薄膜的电子转移速率可以达到 $10^{7}$ $\mathrm{s}^{-1}$ 。2012年，Teng等 ${ }^{46}$ 报道了基于 $\mathrm{CuInS}_{2} / \mathrm{CdS}$ 量子 点的QDSC电池, 电池效率为 $4.2 \%$ 。 McDaniel等 ${ }^{42}$ 合成的 $\mathrm{CuInS}_{1.4} \mathrm{Se}_{0.6}$ 合金量子点带隙只有 $1.3 \mathrm{eV}$, 可 以捕获到近红外光，电池获得 $5.13 \%$ 的认证效率。 钟新华等 ${ }^{47}$ 采用有机高温热注入的方法合成的 $\mathrm{CuInS}_{2}$ 量子点吸收边位于 $900 \mathrm{~nm}$, 并且通过制备 Type-I CuInS $2 / \mathrm{ZnS}$ 核壳量子点, 显著增加了电子的 注入效率和载流子收集效率, 最终使 $\mathrm{CuInS}_{2} / \mathrm{ZnS}$ QDSCs 获得6.66\%的认证效率。CuInTe 2 也是一种IIII-VI族的直接带隙半导体, 与 $\mathrm{CuInS}_{2}$ 和 $\mathrm{CuInSe}_{2}$ 相 比，其体相带隙 $(1.02 \mathrm{eV})$ 更窄，并且具有更强的量 子限制效应和更大的波尔半径, 目前已经被广泛 应用于光伏器件中。 $\mathrm{Kim}$ 等 ${ }^{48}$ 为了提高量子点的稳 定性, 在 $\mathrm{CuInTe} \mathrm{I}_{2}$ 中引入 $\mathrm{Se}$ 成功制备出了 $\mathrm{CuInTe} e_{2-x} \mathrm{Se}_{x}$ 合金量子点, 其吸光范围可至 855 $\mathrm{nm}$ 。此外, $\mathrm{Cu}_{2} \mathrm{ZnSn}(\mathrm{S}, \mathrm{Se})_{4}$ 是一种与 $\mathrm{CuInS}_{2}$ 的光电 性质很相似的材料, 其带隙非常适合用于太阳能 电池 $(1.0-1.8 \mathrm{eV})$, 具有高的吸收系数 $\left(>10^{5} \mathrm{~cm}^{-1}\right)$ 以及很好的光稳定性, 且其组成元素无毒、储量 丰富, 已被用于薄膜太阳能电池中。 $\mathrm{Wu}$ 等 ${ }^{40}$ 合成 了 $\mathrm{Cu}_{2} \mathrm{ZnSnS}_{4}$ 量子点并首次用于 $\mathrm{QDSCs}$ 中, 获得 $17.48 \mathrm{~mA} \cdot \mathrm{cm}^{-2}$ 的短路电流以及 $3.29 \%$ 的效率。

\subsection{4 构建Type-II能级排列量子点}

选择能级匹配的量子点材料构建核壳结构 Type-II能级排列方式, 使量子点的有效带隙变 窄, 拓宽了光吸收范围, 从而增加电池的电流, 也是提高量子点电池效率的有效方法。孟庆波等 ${ }^{49}$ 在 $\mathrm{CuInS}_{2}$ 量子点外面包覆 $\mathrm{Mn}$ 掺杂的 $\mathrm{CdS}$, 随着
$\mathrm{CdS}$ 壳层厚度的增加, $\mathrm{CdS}$ 的导带位置不断下降, 最终与 $\mathrm{CuInS}_{2}$ 量子点形成Type-II的能级排列方式 (图4(a))。如图5所示, $\mathrm{CuInS}_{2} / \mathrm{Mn}-\mathrm{CdS}$ QDSC的光 吸收范围由 $650 \mathrm{~nm}$ 扩展至 $800 \mathrm{~nm}$, 电池的短路电 流达到 $19.29 \mathrm{~mA} \cdot \mathrm{cm}^{-2}$, 电池效率达 $5.38 \%$, 远高于 单独使用 $\mathrm{CuInS}_{2}(1.45 \%)$ 和 $\mathrm{Mn}-\mathrm{CdS}(2.11 \%)$ 量子点效 率之和。此外, 他们还对 $\mathrm{CuInS}_{2} / \mathrm{Mn}-\mathrm{CdS}$ 量子点体 系的载流子传输机制进行了研究, 结果表明 $\mathrm{CuInS}_{2}$ 与 Mn-CdS 层的结合加强了界面反应的波函 数，从而导致核壳结构量子点在空间上的间接带 隙红移，并使光照下 $\mathrm{CdS}$ 导带和 $\mathrm{CuInS}_{2}$ 价带发射的 光生电子-空穴对快速分离, 减少了载流子复合。 使用同样的设计思想，他们制备了 Type-II结构的 $\mathrm{CdSeTe} / \mathrm{CdS}$ QDSC, 效率达到 $5.04 \%{ }^{44}$ 。钟新华等 ${ }^{50,51}$ 制备了Type-II核壳结构的 CdTe/CdSe和ZnTe/ $\mathrm{CdSe}$ 量子点(图4(b)), 借助带有 $-\mathrm{SH}$ 和 $-\mathrm{COOH}$ 基 团的有机小分子将量子点针定在 $\mathrm{TiO}_{2}$ 电极表面, 用 于QDSCs中, 分别获得了高达 6.76\%和7.17\%(认证 效率 $6.82 \%)$ 的效率。 $\mathrm{CdTe} / \mathrm{CdSe}$ 核壳结构量子点敏 化 $\mathrm{TiO}_{2}$ 膜的光吸收范围和电池的IPCE 都达到 900 $\mathrm{nm}$, 且电池的电子注入速率 $\left(1.91 \times 10^{9} \mathrm{~s}^{-1}\right)$ 明显高 于 $\mathrm{CdSe}$ 电池 $\left(0.52 \times 10^{9} \mathrm{~s}^{-1}\right)$, 有效降低了电子复合

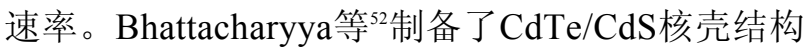
量子点。如图4(c)所示, 通过不断增加 $\mathrm{CdS}$ 壳层厚 度, 使 $\mathrm{CdTe} / \mathrm{CdS}$ 的能带排列方式由 Type-I逐渐转变 为 Type-II, 吸收光谱不断红移, 最终电池获得 $20.19 \mathrm{~mA} \cdot \mathrm{cm}^{-2}$ 的电流和 $6.32 \%$ 的效率。Oron等 ${ }^{53}$ 制 备了 Type-II异质结构的 $\mathrm{CdTe} / \mathrm{CdSe}$ QDSCs, 将电 池的吸收范围拓宽至 $900 \mathrm{~nm}$ 。上述研究结果表 明, 这种Type-II核壳结构量子点不仅可以拓宽量 

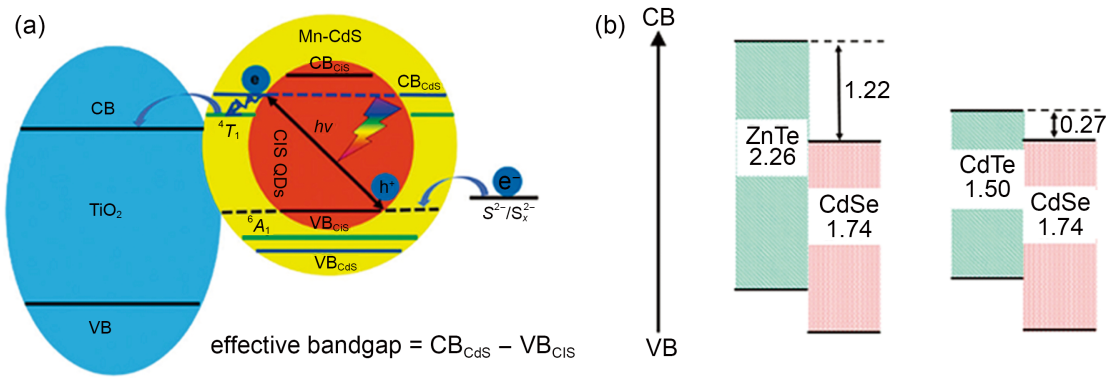

(c)
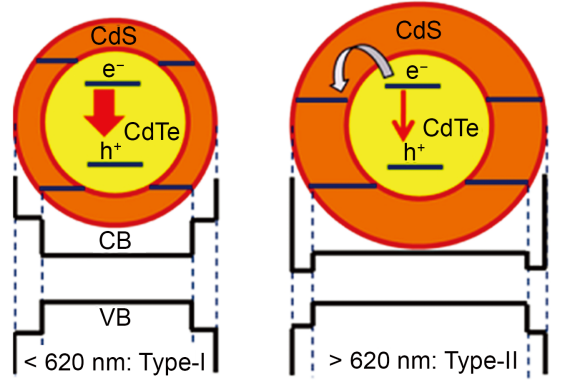

图4 (a) Type-II核壳结构 $\mathrm{CuInS}_{2} / \mathrm{Mn}-\mathrm{CdS}$ QDSC 的载流子转移机制 ${ }^{49} ;$ (b) $\mathrm{ZnTe} / \mathrm{CdSe}$ 和 CdTe/CdSe的体相能带示意图 ${ }^{50,51}$; (c) 随CdS外延层厚度增加, CdTe/CdS由Type-I向Type-II转变的示意图 ${ }^{52}$

Fig.4 (a) Schematic illustration of the possible charge transfer mechanism in Type-II core-shell CuInS $/ \mathrm{Mn}_{2} \mathrm{CdS}_{\mathrm{QDSC}}{ }^{49}$; (b) schematic diagram of band gap between bulk $\mathrm{ZnTe} / \mathrm{CdSe}$ and $\mathrm{CdTe} / \mathrm{CdSe}^{50,51}$; (c) schematic showing two different $\mathrm{CdS}$ epitaxial shell thickness corresponding to Type I to Type II $^{52}$

子点的吸收光谱, 还可以实现电子和空穴在空间 上的分离, 即空穴被局域在核层量子点中, 而电 子则分布在壳层量子点中, 进而增加了电子的抽 取速率, 减少了载流子复合。由此可见, 这种 Type-II量子点体系实现了宽光谱吸收和高效的电 荷分离的同时, 将QDSCs的性能提升到了一个新 的高度。

\section{2 纳晶宽禁带氧化物光阳极}

光阳极是量子点和光生电子传输的载体, 而 不同的光阳极结构对量子点的沉积、光生电子传 输和收集都有很重要的影响。光阳极材料主要包 括 $\mathrm{TiO}_{2}, \mathrm{ZnO}$ 和 $\mathrm{SnO}_{2}$ 三类, 其中 $\mathrm{TiO}_{2}$ 是最常用的光 阳极材料。通常, 光阳极是沉积在FTO导电玻璃衬 底上的纳晶宽禁带氧化物半导体多孔薄膜, 由粒 径为 10-30 $\mathrm{nm}$ 的 $\mathrm{TiO}_{2}$ 纳米颗粒组成的厚度为 5-20 $\mu \mathrm{m}$ 透明层和由粒径为 $300-400 \mathrm{~nm}$ 的 $\mathrm{TiO}_{2}$ 颗粒组成 的双层结构薄膜。10-30 nm TiO 2 颗粒构成的透明 层虽然具有较高的比表面积, 可以沉积更多的 QDs，但其孔径一般较小，孔径分布也很窄，内孔 很容易被量子点堵塞, 不利于电解液的渗透和电 解质的扩散。孟庆波等 ${ }^{18}$ 通过大、小粒径 $\mathrm{TiO}_{2}$ 纳米 颗粒来调控光阳极的表面积、孔径尺寸和孔隙 率, 提高了光捕获效率(LHE)和电子转移产率, 最
终 $\mathrm{CdS} / \mathrm{CdSe}$ 共敏化 $\mathrm{TiO}_{2}$ 电池体系获得了 $4.92 \%$ 的效 率。尽管这些由纳米颗粒组成的多孔薄膜可以提 供足够的比表面积用于量子点的吸附, 但这种纳 晶多孔薄膜存在大量晶界且无规则的电子传输使 得电池复合比较严重, 在一定程度上制约了电池 性能的进一步发展。因此, 有序的纳米结构(纳米 线, 纳米管等)被用来取代这种多孔结构的光阳 极, 目的在于改善电子传输过程, 减少载流子复 合。孟庆波等 ${ }^{4}$ 以 $\mathrm{ZnO}$ 纳米线作为模板辅助在 FTO玻璃上制备 $\mathrm{TiO}_{2}$ 纳米管阵列, 尽管纳米管长度 仅有 $3 \mu \mathrm{m}$, 仍然获得了 $4.61 \%$ 的效率。Hong等 ${ }^{55}$ 用 脉冲激光法(PLD)生长 $\mathrm{TiO}_{2}$ 纳米棒等级结构, 通过 优化量子点的沉积参数, 电池效率达到 $5.57 \%$ 。 Kuang 等 ${ }^{20}$ 发展了一种分等级结构 $\mathrm{TiO}_{2}$ 纳米线包覆 的 $\mathrm{TiO}_{2}$ 空心球结构光阳极, 这种结构为量子点的负 载提供了足够的表面积和快速有序的电子传输路 径, 同时增强了光散射能力, 提高了对太阳光的 利用率, 从而使 $\mathrm{CdS} / \mathrm{CdSe}$ 共敏化的 $\mathrm{QDSC}$ 获得 $19.32 \mathrm{~mA} \cdot \mathrm{cm}^{-2}$ 的短路电流, 电池效率突破 $6 \%$ 。

除了 $\mathrm{TiO}_{2}$, 其它的宽禁带半导体材料(如 $\mathrm{ZnO} 、 \mathrm{SnO}_{2}$ ) 也被用作QDSCs 光阳极。 $\mathrm{SnO}_{2}$ 的电子 迁移率大于 $\mathrm{TiO}_{2}$, 具有更快的电子扩散速率, 被用 来替代 $\mathrm{TiO}_{2}$ 作为 $\mathrm{QDSCs}$ 的光阳极, 并且 $\mathrm{SnO}_{2}$ 的导带 

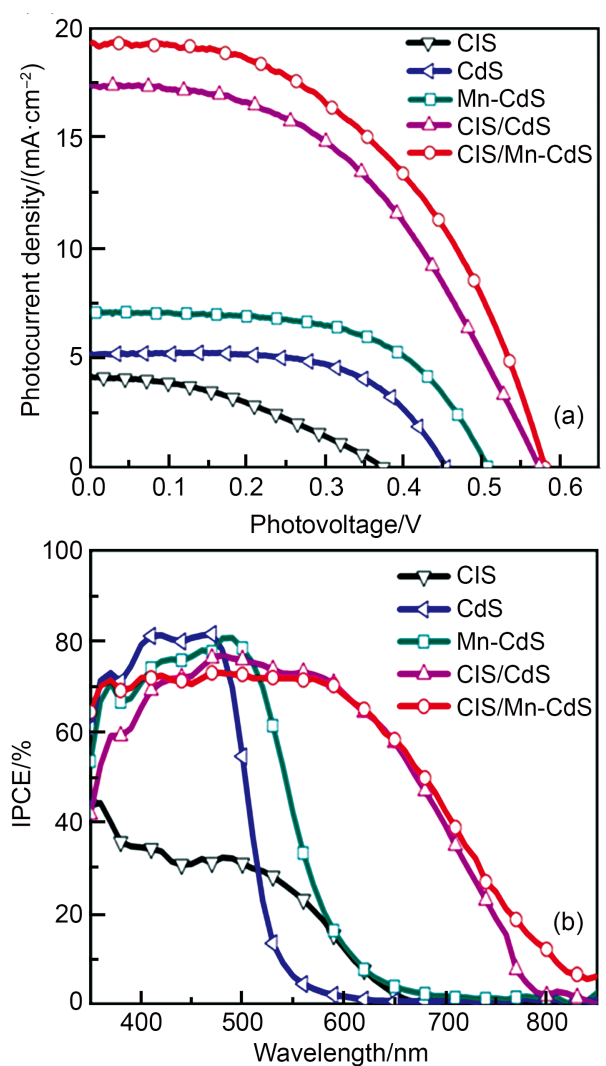

图5 (a) 量子点敏化太阳能电池的 $J-V$ 特性对比; (b) 电池 的光电转换效率(IPCE) 谱 ${ }^{49}$

Fig.5 (a) Comparison of the $J-V$ characteristics of QDSCs; (b) incident photon to current conversion efficiency (IPCE) spectra of the QDSCs ${ }^{49}$

位置比 $\mathrm{TiO}_{2}$ 的高, 更有利于光生电子的注入 ${ }^{56,57}$ 。王 庆等 ${ }^{58,59}$ 用 $\mathrm{SnO}_{2}$ 作为光阳极, 在 $\mathrm{CdS} / \mathrm{CdSe}$ 和 $\mathrm{PbS}$ / $\mathrm{CdS}$ 共敏化体系中分别获得了 17.4 和 $17.34 \mathrm{~mA} \cdot \mathrm{cm}^{-2}$ 的电流, 均高于 $\mathrm{TiO}_{2}$ 作为光阳极的电流。 $\mathrm{ZnO}$ 是一 种高迁移率的 $n$ 型氧化物半导体, 其纳米结构易于 制备且形貌丰富(包括纳米棒、纳米线等)。C $\mathrm{Ca}$ 等 ${ }^{60}$ 采用 $\mathrm{H}_{3} \mathrm{BO}_{3}$ 和 $\left(\mathrm{NH}_{4}\right)_{2} \mathrm{TiF}_{6}$ 处理基于 $\mathrm{ZnO}$ 纳米颗粒和微 球双层结构的光阳极, 获得了 $5.08 \%$ 的效率。孟庆 波等 ${ }^{61}$ 首次采用简单的刮涂法将 $20 \mathrm{~nm}$ 的 $\mathrm{ZnO}$ 纳米 颗粒制备成多孔膜，用作 CdS/CdSe QDSCs 电池的 光阳极, 电池获得 $4.46 \%$ 的转换效率和高达 0.683 $\mathrm{V}$ 的开路电压。Yang等 ${ }^{62}$ 利用 $\mathrm{ZnO}$ 纳米棒、四角纳 米棒双层结构作为光阳极获得了 $5.24 \%$ 的效率, 这 种结构可以提高量子点的沉积量, 增强光散射的 同时降低串联阻抗。随后他们用准量子阱 $\mathrm{ZnSe} / \mathrm{CdSe} / \mathrm{ZnSe}$ 多层量子点敏化四角纳米棒光阳 极, 该体系具有较长的扩散长度, 电荷分离效率 高, 效率达到了 $6.20 \%$ 。

\section{3 量子点在光阳极的沉积}

\subsection{1 量子点原位沉积法}

原位沉积方法分为化学浴沉积(CBD) 方法和连 续离子层吸附与反应(SILAR)方法, 沉积过程如图 6所示。CBD法是指将 $\mathrm{TiO}_{2}$ 膜浸泡在含有量子点阴 阳离子的前驱液中, 在一定的温度下, 通过缓慢 释放活性阴阳离子从而在 $\mathrm{TiO}_{2}$ 膜上成核、生长量子 点。SILAR法是在CBD法的基础上发展而来的, 即 将 $\mathrm{TiO}_{2}$ 膜交替进入含有量子点阳离子和阴离子的前 驱液中原位成核和生长量子点, 实现一定程度可 控的量子点沉积。CBD和SILAR 这两种沉积方法 依赖于量子点自身的成核生长, 制备过程简单, 所制备出的量子点具有多分散特性, 在 $\mathrm{TiO}_{2}$ 膜上的 覆盖率高, 并且由于量子点与金属氧化物 $\left(\mathrm{TiO}_{2}\right)$ 连 接紧密, 因而电子注入效率也很高。在QDSCs发 展之初, SILAR和CBD这两种量子点原位沉积方法 被广泛使用, 电池效率不断提升。特别是, 通过 发展新的光阳极结构及对量子点能带调控, 基于 原位沉积方法制备的QDSCs效率也在逐渐提高。 如, $\mathrm{CaO}^{\text {等 }}{ }^{64}$ 采用简单的 $\mathrm{CBD}$ 法在 $\mathrm{TiO}_{2}$ 表面沉积了 $\mathrm{Mn}^{2+}$ 掺杂的 $\mathrm{CdSe}, \mathrm{Mn}^{2+}$ 的掺入增加了光吸收, 提高 了 $\mathrm{CdSe}$ 的导带位置, 从而增加了电子注入驱动 力, 减少了载流子复合, $\mathrm{Cd}_{0.8} \mathrm{Mn}_{0.2} \mathrm{Se}$ 基电池获得 $6.33 \%$ 的高效率。Wang 等 ${ }^{21}$ 采用SILAR和CBD法在 $\mathrm{TiO}_{2}$ 表面沉积了 $\mathrm{CdS} / \mathrm{CdSe}$ 量子点, 并结合 $\mathrm{Cu}_{2-x} \mathrm{Se}$ 对 电极, 最终电池获得 $7.11 \%$ 的高效率。尽管基于原
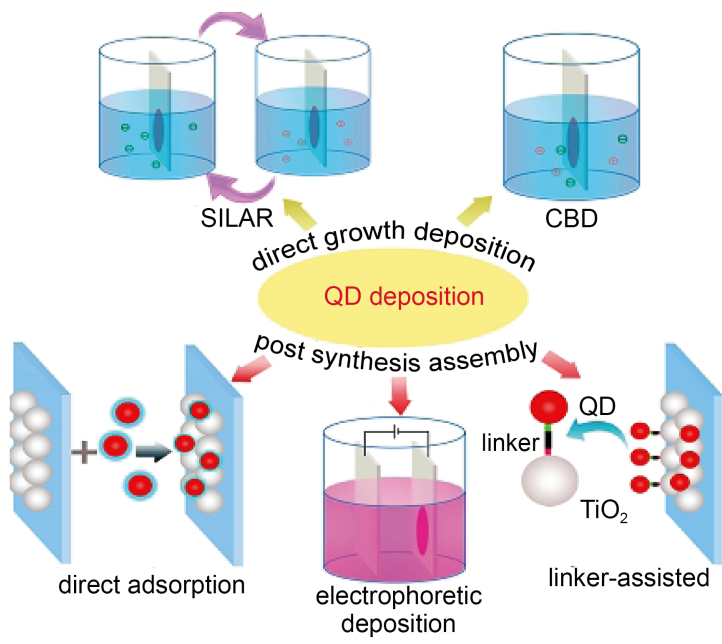

图6 量子点的沉积方法示意图 ${ }^{65}$

Fig.6 Schematic diagram of the deposition methods of QDs ${ }^{65}$

CBD: chemical bath deposition, SILAR: successive ion layer adsorption and reaction 
位沉积方法所制备的量子点敏化电池效率在不断 提高, 但是, 这种原位沉积方法的发展也受到很 大局限, 尤其是适用于原位沉积方法的量子点种 类少，只有 $\mathrm{CdS} 、 \mathrm{CdSe} 、 \mathrm{PbS}$ 和 $\mathrm{Sb}_{2} \mathrm{~S}_{3}$ 等几种材料， 电池效率提升的空间受到很大限制。

\subsection{2 非原位预先合成量子点及其在光阳极的 沉积}

尽管原位沉积量子点方法简单, 量子点在光 阳极表面覆盖率高, 但存在量子点晶体质量不 佳, 粒径分布不均匀以及表面缺陷多等缺点。而 采用非原位预先合成量子点方法可以控制量子点 的生长机制、粒径和晶体质量, 从而获得高质 量、表面缺陷少的量子点。近年来, 采用这种非 原位预先合成方法所得到的量子点被应用在 QDSCs中, 并展现出了优势, 受到越来越多的关 注。

原位的预先合成量子点用于QDSCs的关键在 于提高量子点在光阳极上的沉积量。如图7所示,

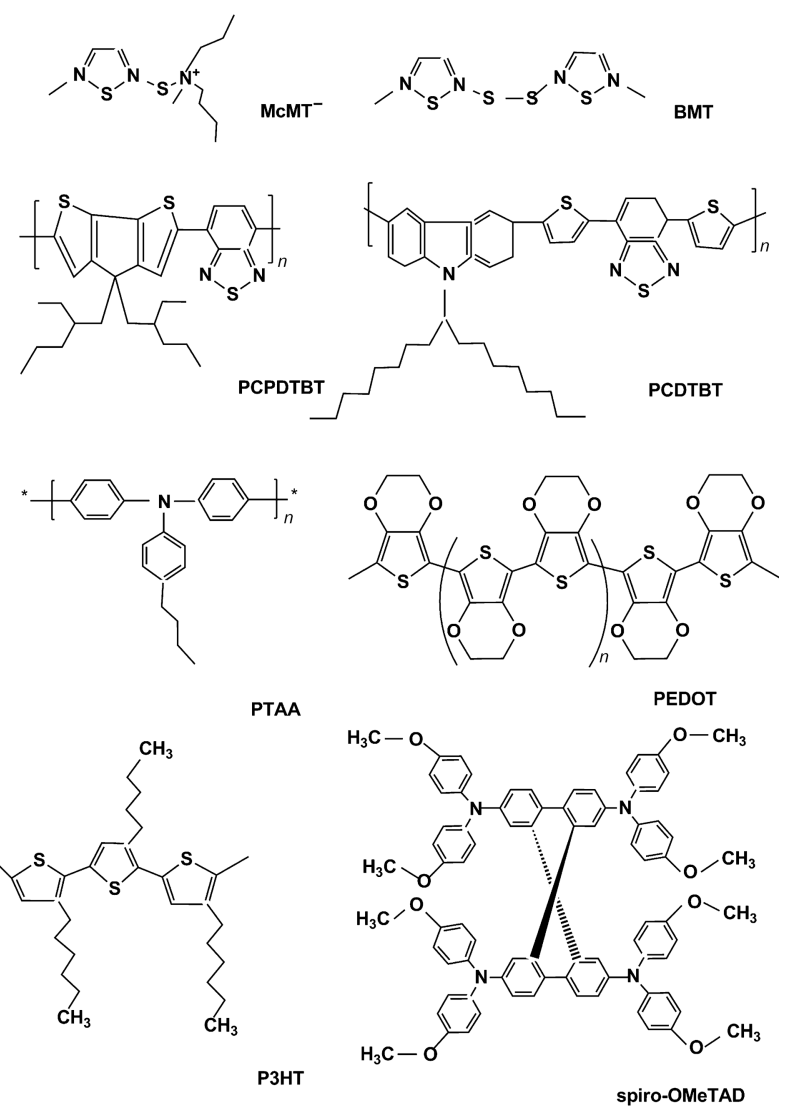

图7 有机氧化还原电对和一些空穴传输材料的 分子结构示意图

Fig.7 Molecular structure of organic redox couple and some hole transport materials
目前此类量子点在光阳极上的沉积方法主要包括 直接物理吸附、双官能团辅助自组装吸附、电泳 沉积等。直接物理吸附法是将 $\mathrm{TiO}_{2}$ 膜浸泡在预先合 成的量子点溶液中进行长时间吸附, 这种方法操 作简便, 但纯化后的量子点易团聚且容易出现量 子点在 $\mathrm{TiO}_{2}$ 膜上吸附不均匀等问题。电泳沉积法主 要利用电场对量子点的驱动力, 加速其在电极上 沉积, 目前在QDSCs中的应用相对较少。Santra等66 用电沉积法将 $\mathrm{CuInS}_{2}$ 量子点沉积在 $\mathrm{TiO}_{2}$ 上, 电池效 率达到 $3.9 \%$ 。 Kuang 等 ${ }^{67}$ 采用电沉积法在分等级结 构 $\mathrm{TiO}_{2}$ 微米球上沉积 $\mathrm{CdS}$ 和 $\mathrm{CdSe}$ 量子点, 这种方法 使得量子点在 $\mathrm{TiO}_{2}$ 表面获得高的覆盖率以及很好的 连接性, 促进了量子点对光的利用和电子的注入 效率，最终使 $\mathrm{CdS} / \mathrm{CdSe}$ 获得 $98 \%$ 的电子收集效率 和 $4.81 \%$ 的光电转换效率。

双官能团辅助自组装吸附主要是利用两端的 官能团分别将量子点与 $\mathrm{TiO}_{2}$ 连接从而实现量子点的 敏化, 如图4所示 ${ }^{68}$ 。在QDSCs 发展早期, 使用这 种方法进行量子点敏化的电池效率远低于使用 SILAR或CBD沉积方法, 主要是由于配体置换不完 全和溶剂极性不匹配造成量子点在氧化物光阳极 表面覆盖率低且容易聚集。近年来, 随着量子点 合成方法、配体置换及吸附技术的不断发展, 这 种双官能团辅助法展现出了很大优势, 电池效率 取得了很大突破。

目前, 量子点的合成方法分为水相合成和有 机高温合成两种。水相法合成量子点制备过程简 单, 通常在室温或较低温度 $\left(<200{ }^{\circ} \mathrm{C}\right)$ 下即可完 成, 合成过程主要是将反应前驱物混合溶解在水 中, 加入反应活性剂(常用的有颈基丙酸(MPA), 颈基乙酸(TGA)等), 随后用 $\mathrm{NaOH}$ 调节溶液 $\mathrm{pH}$ 值, 最终通过反应时间及温度来控制量子点的粒径, 值得一提的是将所合成的胶体量子点应用于 QDSCs 时不需要配体交换而直接通过表面官能团 实现量子点敏化。孟庆波等 ${ }^{49,69}$ 首次采用简单的水 相法在室温下制备了 TGA包覆的 $\mathrm{CuInS}_{2}$ 胶体量子 点, 利用 TGA两端的颈基和羧基官能团分别与量 子点和 $\mathrm{TiO}_{2}$ 连接实现 $\mathrm{CuInS}_{2}$ 量子点的敏化, 随后通 过在CuInS ${ }_{2}$ 表面包覆Mn掺杂的CdS形成Type-II核壳 异质结量子点, 实现了光谱的拓宽和高效的电荷 分离, 最终获得 5.38\%的高效率。此外, 他们采用 微波辅助法快速高效地制备了 $\mathrm{CdSe}_{x} \mathrm{Te}_{1-x} / \mathrm{CdS}$ 胶体 量子点, 并进一步用SILAR法沉积CdS拓宽了吸收 
光谱, 使电池效率达到了 $5.04 \%{ }^{44}$ 。Sahasrabudhe 和Bhattacharyy $\mathrm{a}^{52}$ 以 $\mathrm{CdCl}_{2}$ 和 $\mathrm{NaHTe}$ 为前驱物, MPA作为配体, 制备了水相的 $\mathrm{CdTe}$ 量子点, 并借 助MPA两端的官能团将 $\mathrm{CdTe}$ 组装到 $\mathrm{TiO}_{2}$ 表面, 所 制备的电池最终获得 $6.41 \%$ 的高效率。

与水相合成的量子点不同, 有机高温法得到 的油相量子点晶体质量更高, 但是用于QDSCs电 池中时需要进行配体交换, 即通常用MPA或 TGA等短链配体将量子点表面的长链配体置换下 来, 再将量子点从油相置换到水相, 这样才有利 于量子点吸附到 $\mathrm{TiO}_{2}$ 表面。2012年, 钟新华等 ${ }^{22}$ 采 用有机高温的方法原位制备了反转 Type-I型 $\mathrm{CdS} / \mathrm{CdSe}$ 核壳量子点, 通过配体交换成功将量子 点由油相转为水相, 并发展了一种快速、有效的 沉积方法将量子点吸附在 $\mathrm{TiO}_{2}$ 表面, 最终获得 5.32\%的电池效率。通过探讨吸附时间对量子点在 $\mathrm{TiO}_{2}$ 表面吸附的影响, 他们发现量子点在多孔膜上 的吸附随时间逐渐增加, 并在 $2 \mathrm{~h}$ 达到饱和, 量子 点覆盖率可以达到 $34 \%$; 元素分析结果表明, $\mathrm{Cd} / \mathrm{Ti}$ 元素比例随 $\mathrm{TiO}_{2}$ 膜厚度增加保持不变, 证明 该方法可以实现量子点在 $\mathrm{TiO}_{2}$ 介孔膜中的均匀吸 附。此后, 他们将这种量子点的沉积方法成功用 于 $\mathrm{CdSe}_{x} \mathrm{Te}_{1-x} 、 \mathrm{CdTe} / \mathrm{CdSe} 、 \mathrm{ZnTe} / \mathrm{CdSe} 、 \mathrm{CuInS}_{2}$ 、 $\mathrm{CuInSe}_{2}$ 等QDSCs 中 $^{50,51,70,71}$, 电池获得 $6 \%-8 \%$ 的高效 率。尤其是他们制备的 $\mathrm{CdTe} / \mathrm{CdSe}$ 和 $\mathrm{ZnTe} / \mathrm{CdSe}$ 电 池, 进一步证明了 Type-II结构的QDSCs不仅可以 实现宽光谱吸收, 具有高的电子注入和电荷收集 效率, 还可以有效地减少复合, 获得更好的电池 性能 ${ }^{50,51}$ 。2015 年, 钟新华等 ${ }^{10}$ 通过对 $\mathrm{TiO}_{2} /$ $\mathrm{CdSe}_{x} \mathrm{Te}_{1-x}$ 表面依次沉积 $\mathrm{ZnS}$ 和 $\mathrm{SiO}_{2}$ 有效抑制了复 合, 大幅提高了开路电压, 最终获得 $8.21 \%$ 的认证 效率，这也是目前液相QDSCs的最高效率。

\subsection{QDSCs 电池光阳极的表面修饰方法}

近年来, 尽管QDSCs得到快速发展, 但其效 率仍远低于 DSCs, 其中较低的光生电子注入效率 及严重的载流子复合是限制其效率的主要原因。 QDSCs中载流子的复合主要发生在 $\mathrm{TiO}_{2} /$ 电解质、 $\mathrm{TiO}_{2} / \mathrm{QDs}$ 及QDs/电解质这三个界面, 因此, 对光 阳极表面及量子点表面进行修饰或预处理, 以减 少载流子复合是至关重要的。目前主要包括以下 几种表面处理方法:

(1) 在 $\mathrm{TiO}_{2} / \mathrm{QDs}$ 表面或界面引入量子点进行针 化或作为缓冲层, 最常用的有 $\mathrm{ZnS} 、 \mathrm{ZnSe}$ 以及
$\mathrm{CdS}$ 等。 $\mathrm{Kim}^{\text {等 }}{ }^{72}$ 用 $\mathrm{Mn}$ 掺杂 $\mathrm{ZnSe}$ 取代最常用的 $\mathrm{ZnS}$ 作为钝化层用于 $\mathrm{CdS} / \mathrm{CdSe} \mathrm{QDSCs}$ 中, 有效提 高了载流子的收集效率, 减小了复合, 电池获得 $5.67 \%$ 的效率。林原等 ${ }^{73}$ 在 $\mathrm{CdSe}$ 量子点外面包覆晶 格过渡层 $\mathrm{CdS}$, 有效降低了电子的复合速率, 阻挡 了量子点与电解液的复合反应。

(2) 在 $\mathrm{TiO}_{2} / \mathrm{QDs}$ 表面沉积薄层的氧化物 $\left(\mathrm{Al}_{2} \mathrm{O}_{3}\right.$ 、 $\mathrm{SiO}_{2} 、 \mathrm{MgO} 、 \mathrm{ZrO}_{2} 、 \mathrm{TiO}_{2}$ 等) 来减少复合 ${ }^{74,75}$ 。 Chen等 ${ }^{76}$ 在 $\mathrm{TiO}_{2} / \mathrm{CdS}$ 沉积了 $\sim 2 \mathrm{~nm}$ 厚的 $\mathrm{TiO}_{2}$ 超薄层减 小了载流子复合, 并提高了电池的稳定性。钟新 华等 ${ }^{10}$ 对 $\mathrm{TiO}_{2} / \mathrm{CdSeTe}$ 表面进行 $\mathrm{ZnS} / \mathrm{SiO}_{2}$ 双层处理不 仅有效避免了量子点的光腐蚀, 同时减少了光阳 极和电解质界面的复合, 提高了电池的稳定性和 寿命, 将开路电压从 $0.583 \mathrm{~V}$ 提高到 $0.653 \mathrm{~V}$, 电池 效率提高了 $20 \%$ 。

(3) 构建Type-II结构来提高电子的注入效率, 进而减少复合。韩礼元等 ${ }^{77}$ 在 $\mathrm{TiO}_{2}$ 与 $\mathrm{CdSe}$ 之间引入 $\mathrm{CdS}_{1-x} \mathrm{Se}_{x}$ 中间层, 通过改变 $\mathrm{S}$ 与 $\mathrm{Se}$ 的比例来调节 $\mathrm{CdS}_{1-x} \mathrm{Se}_{x}$ 导带位置, 使 $\mathrm{TiO}_{2}$ 和 $\mathrm{CdS}_{1-x} \mathrm{Se}_{x}$ 以及 $\mathrm{CdS}_{1-x} \mathrm{Se}_{x}$ 和CdSe形成Type-II能带排列方式, 提高了 电子的注入效率，减少了复合，电流得到 $17.8 \%$ 的 提升。

(4) 在量子点表面引入无机配体进行预处理。 王立铎研究组 ${ }^{78}$ 通过对 $\mathrm{TiO}_{2} / \mathrm{CdS}$ 表面进行无机 $\mathrm{I}^{-}$配 体预处理并沉积 $\mathrm{ZnS}$ 层, 有效减少了量子点表面缺 陷态, 从而减少了QDSCs中的载流子复合, 提高 了电池性能。Agren等 ${ }^{79}$ 同时采用MPA和碘离子对 $\mathrm{CdSe}$ 表面进行杂化针化, 减少了量子点表面的缺 陷和复合, 相比于量子点表面只有MPA的电池, 转换效率提高了 $41 \%$ 。

\section{QDSCs 电池其他组成部分的研究进展 4.1 电解质}

电解质主要用来还原再生量子点, 对电池的 光电性能和稳定性有着至关重要的影响。由于 DSCs 常用的 $\mathrm{I}_{3}^{-} / \mathrm{I}^{-}$氧化还原电对有强氧化性, 对量 子点有腐蚀作用, 会导致光电流的快速衰减, 因 此, QDSCs一般采用由 $\mathrm{S}$ 和 $\mathrm{Na}_{2} \mathrm{~S}$ 的水溶液组成的电 解质(含有 $\mathrm{S}^{2-} / \mathrm{S}_{x}^{2-}$ 氧化还原电对)来稳定其性能。尽 管目前高效的 QDSCs 都以 $\mathrm{S}^{2-} / \mathrm{S}_{x}^{2-}$ 作为电解质, 但 QDSCs的开路电压值大多低于 $0.7 \mathrm{~V}$, 填充因子也 很低, 一般低于 0.65 。因此, 采用非硫氧化还原电 对有利于提高电池的开路电压, 目前用于QDSCs 
的非硫氧化还原电对或电解质体系如图7所示 ${ }^{80}$ 。

Sun等 ${ }^{81}$ 将 $\left[\left(\mathrm{CH}_{3}\right)_{4} \mathrm{~N}\right]_{2} \mathrm{~S} /\left[\left(\mathrm{CH}_{3}\right)_{4} \mathrm{~N}\right]_{2} \mathrm{Sn}$ 作为氧化还 原电对用于CdS QDSC体系中, 获得 $1.2 \mathrm{~V}$ 的高电压 和 0.89 的超高填充因子, 电池获得了 $3.2 \%$ 的效率。 随后他们以四甲基硫腿作为电解质, 在 $\mathrm{ZnSe} / \mathrm{CdS}$ 体系中获得了较高的填充因子 ${ }^{82}$ 。此外, 基于液态 电解质的QDSCs 存在易挥发以及腐蚀等问题, 容 易造成电池封装过程中电解质的泄露, 不利于电 池的长期稳定性, 因此发展固态或准固态电解质 逐渐成为研究重点之一 ${ }^{83}$ 。孟庆波等84将丙烯酰胺和 甲叉双丙烯酰胺聚合制备的凝胶浸泡在多硫电解 质中形成了准固态电解质(图8(a)), 将该电解质用 于 $\mathrm{CdS} / \mathrm{CdSe}$ 量子点敏化太阳能电池中获得了 $4.0 \%$ 的效率。此外, 他们还制备了薄膜凝胶电解 质, 如图 8(b) 所示, 电池获得 $4.0 \%$ 的转换效率 ${ }^{85}$ 。 Yang 和Wang ${ }^{86}$ 将 $\mathrm{S}$ 和四甲基硫酸铵(TMAS) 作为氧 化还原剂添加到聚氧化乙烯(PEO)和聚偏氟乙烯 (PVDF) 的混合物中制备了固态电解质, 制备的固 态QDSCs 与液结QDSCs相比, 具有更高的IPCE以 及更好的稳定性。

\section{2 对电极}

对电极是QDSCs电池的一个重要组成部分, 承担着催化还原电解质的作用。对电极应该具有 高的催化活性和导电性。在DSCs中广泛使用的 $\mathrm{Pt}$ 电极并不适合作为 QDSCs的对电极, 主要由于

(a)

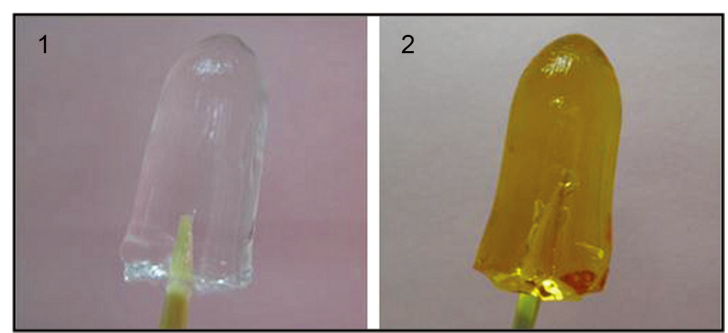

(b)

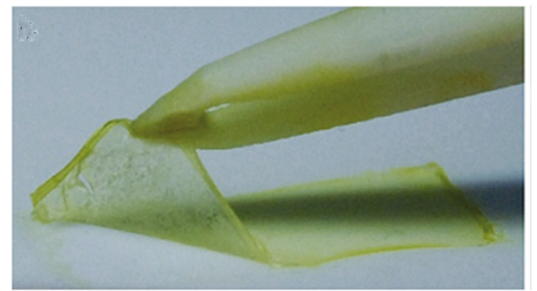

图8 (a) 浸泡电解质之前(1)和含有 $\mathrm{S}^{2-} / \mathbf{S}_{x}^{2-}$ 的聚合物凝胶电 解质 $(2)$ 照 片 $^{84}$; (b) 吸附含有 $S^{2-} / S_{x}^{2-}$ 氧化还原电对电解液后 的魔芋葡甘露聚糖薄膜 85

Fig.8 Photographs of the hydrogel (1) and the $S^{2-} / S_{x}^{2-}$ based polymer gel electrolyte (2) ${ }^{84}$; (b) $\mathrm{S}^{2-} / \mathrm{S}_{x}^{2-}$ electrolyte infiltrated Konjac glucomannan (KGM) thin film ${ }^{85}$
$\mathrm{Pt}$ 与多硫氧化还原电对有很强的化学键合作用, 其 催化活性较差, 从而造成较低的填充因子和电池 效率。研究结果表明, $\mathrm{Cu}_{2} \mathrm{~S} 、 \mathrm{CuS} 、 \mathrm{PbS} 、 \mathrm{CoS}$ 、 $\mathrm{NiS} 、 \mathrm{CuInS}{ }_{2}$ 等金属硫化物作为QDSCs电池的对电 极材料时电池的开路电压和电流相比于Pt都有明显 提升 ${ }^{87-93}$ 。目前常用的 $\mathrm{Cu}_{2} \mathrm{~S}$ 对电极是在盐酸腐蚀过 的黄铜片上原位制备得到的 $\mathrm{Cu}_{2} \mathrm{~S} / \mathrm{Cu}$ 对电极, 这种 以铜片作为基底的对电极存在连续腐蚀、机械性 能较差、难以封装等问题。孟庆波等 ${ }^{93-95}$ 在FTO基 底上制备了 $\mathrm{Cu}_{2} \mathrm{~S} / \mathrm{C} 、 \mathrm{PbS} / \mathrm{C} 、 \mathrm{CuInS}_{2} / \mathrm{C}$ 复合电极并 用于 $\mathrm{CdS} / \mathrm{CdSe}$ 共敏化的QDSCs中, 电池效率分别 达到了 $3.71 \% 、 3.91 \%$ 和 $4.32 \%$ 。研究发现，金属硫 化物与碳材料复合, 可以有效提高对电极的稳定 性, 同时可增加对电极的比表面积, 提高催化活 性位点。在此工作基础上, 基于 $\mathrm{Cu}_{2} \mathrm{~S} / \mathrm{C}$ 对电极, 孟 庆波等 ${ }^{96}$ 制备了面积为 $12 \mathrm{~cm}^{2}$ 的电池模块, 电池效 率为 $2.31 \%$, 见图 9 。 $\mathrm{Kim}$ 等 ${ }^{97}$ 以聚乙烯吡咯烷酮 $(\mathrm{PVP})$ 为溶剂, 在 $\mathrm{FTO}$ 玻璃上 $\mathrm{CBD}$ 沉积 $\mathrm{CuS}$ 薄膜作 为对电极, 制备的 $\mathrm{CdS} / \mathrm{CdSe}$ 电池获得 $5.22 \%$ 的效 率。Punnoose等 ${ }^{90}$ 用水热法制备的 $\mathrm{CoS}_{2}$ 对电极在多 硫电解质中表现出了比Pt更高的催化活性。Lee等98 用 $\mathrm{Au} / \mathrm{CuS}$ 作为 $\mathrm{PbS}$ QDSC对电极获得 $5.73 \%$ 的效 率。 $\mathrm{Kamat}$ 等 ${ }^{99}$ 用 $\mathrm{RGO} / \mathrm{Cu}_{2} \mathrm{~S}$ 复合对电极获得 $5.40 \%$ 的电池效率。钟新华等 ${ }^{43}$ 在FTO玻璃上电镀 金属 $\mathrm{Au}$ 膜, 然后再用多硫电解质腐蚀获得 $\mathrm{Cu}_{2} \mathrm{~S}$ 对 电极, $\mathrm{CdSe}_{x} \mathrm{Te}_{1-x}$ 量子点敏化太阳能电池获得了 $6.36 \%$ 的效率。此外, Yong等 ${ }^{100}$ 用 Mo化合物 $\left(\mathrm{Mo}_{2} \mathrm{~N}\right.$, $\mathrm{Mo}_{2} \mathrm{C}$ 及 $\mathrm{MoS}_{2}$ )与 $\mathrm{CNT}$ 和RGO制备了复合对电极, 效 率分别达到 $5.41 \%$ 、4.84\%和 $3.44 \%$ 。Bang 等 ${ }^{101}$ 用 $\mathrm{Cu}_{1.8} \mathrm{Se}$ 和 $\mathrm{PbSe}$ 对电极在 $\mathrm{CdS} / \mathrm{CdSe}$ 体系分别获得了 $5.01 \%$ 和 $4.71 \%$ 的效率。

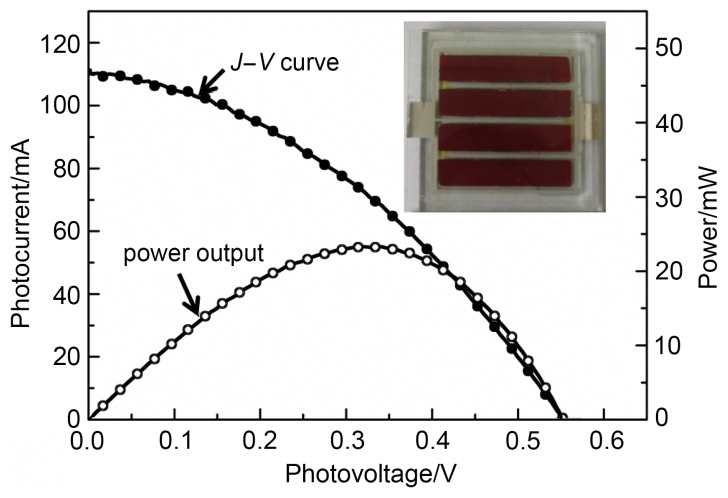

图9 $\mathrm{CdS} / \mathrm{CdSe}$ 量子点敏化太阳能电池模块 ${ }^{96}$

Fig.9 CdS/CdSe quantum dot solar cell module ${ }^{96}$ 


\section{5 结论与展望}

量子点独特的光电特性使QDSCs成为一种具 有发展潜力的新型太阳能电池。但目前光电转换 效率仍低于DSCs、有机太阳能电池及钙钛矿太阳 能电池等新型太阳能电池。制约QDSCs 效率的主 要因素包括: 量子点材料本身较多的表面缺陷态 及其在 $\mathrm{TiO}_{2}$ 表面的负载量偏低, 光生电子注入和收 集效率不理想，量子点/光阳极与电解质之间严重 的载流子复合以及由于 $\mathrm{S}^{2-} / \mathrm{S}_{x}^{2-}$ 氧化还原电对和对 电极导致的开路电压和填充因子偏低等。

实现高质量、宽吸收量子点在 $\mathrm{TiO}_{2}$ 光阳极表面 的高负载量是进一步提高QDSCs性能的关键。因 此, 优化 $\mathrm{TiO}_{2}$ 光阳极的形貌和结构, 提高量子点在 光阳极上的覆盖率及光生电子收集能力也是未来 的发展方向之一。而为了获得宽光谱吸收的量子 点材料, 采用合金量子点及设计Type-II核壳量子 点已经成为量子点敏化剂的发展趋势。因此, 进 一步发展量子点的制备工艺以期获得表面缺陷 少、高质量的量子点, 特别是设计制备成本低、 低毒、禁带宽度窄、消光系数高的高质量环境友 好的量子点敏化剂, 优化双官能团辅助自组装或 其它量子点沉积方法, 发展新颖的表面修饰或预 处理方法有效解决量子点在 $\mathrm{TiO}_{2}$ 中快速渗透、均匀 吸附、高负载量等问题, 减少载流子复合, 是进 一步提升胶体量子点QDSCs效率的有效手段。特 别是，如何利用 “多激子效应” 提高电池效率仍然 是一个世界性的难题, 也是今后进一步提升QDSCs 性能的发展方向。我们相信：随着QDSCs研究的 不断深入, QDSCs将获得新的更大的进展。

\section{References}

(1) Gorer, S.; Hodes, G. J. Phys. Chem. 1994, 98, 5338. doi: 10.1021/j100071a026

(2) Yu, W. W.; Qu, L.; Guo, W.; Peng, X. Chem. Mater. 2003, 15, 2854. doi: $10.1021 / \mathrm{cm} 034081 \mathrm{k}$

(3) Schaller, R. D.; Agranovich, V. M.; Klimov, V. I. Nat. Phys. 2005, 1, 189. doi: 10.1038/nphys 151

(4) Kamat, P. V. J. Phys. Chem. Lett. 2013, 4, 908. doi: $10.1021 / \mathrm{jz} 400052 \mathrm{e}$

(5) Bai, Y.; Mora-Sero, I.; Angelis, F. D.; Bisquert, J.; Wang, P. Chem. Rev. 2014, 114, 10095. doi: 10.1021/cr400606n

(6) Garey, G. H.; Abdelhady, A. L.; Ning, Z.; Thon, S. M.; Bakr, O. M.; Sargent, E. H. Chem. Rev. 2015, 115, 12732. doi: 10.1021/acs.chemrev.5b00063.

(7) Hodes, G. J. Phys. Chem. C 2008, 112, 17778. doi: $10.1021 / j p 803310$ s
(8) Piliego, C.; Protesescu, L.; Bisri, S. Z.; Kovalenko, M. V.; Loi, M. A. Energy Environ. Sci. 2013, 6, 3054. doi: $10.1039 / \mathrm{c} 3$ ee $41479 \mathrm{e}$

(9) Vogel, R.; Hoyer, P.; Weller, H. J. Phys. Chem. 1994, 98, 3183. doi: $10.1021 / \mathrm{j} 100063 \mathrm{a} 022$

(10) Zhao, K.; Pan, Z.; Mora-Sero, I.; Canovas, E.; Wang, H.; Song, Y.; Gong, X.; Wang, J.; Bonn, M.; Bisquert, J.; Zhong, X. J. Am. Chem. Soc. 2015, 137, 5602.

(11) Kim, J. Y.; Yang, J.; Yu, J. H.; Baek, W.; Lee, C. H.; Son, H. J.; Hyeon, T.; Ko, M. J. ACS Nano 2015, 9, 11286.

(12) Wei, H.; Wang, G.; Luo, Y.; Li, D.; Meng, Q. Electrochim. Acta 2015, 173, 156. doi: 10.1016/j.electacta.2015.05.052

(13) Mathew, S.; Yella, A.; Cao, P.; Humphry-Baker, R.; Curchod, B. F. E.; Ashari-Astani, N.; Tavernelli, I.; Rothlisberger, U.; Nazeeruddin, M. K.; Grätzel, M. Nat. Chem. 2014, 6, 242. doi: 10.1038/nchem. 1861

(14) Shen, Q.; Kobayashi, J.; Diguna, L. J.; Toyoda, T. J. Appl. Phys. 2008, 103, 084304. doi: 10.1063/1.2903059

(15) Diguna, L. J.; Shen, Q.; Kobayashi, J.; Toyoda, T. Appl. Phys. Lett. 2007, 91, 023116. doi: 10.1063/1.2757130

(16) Toyoda, T.; Yindeesuk, W.; Okuno, T.; Akimoto, M.; Kamiyayama, K.; Hayase, S.; Shen, Q. RSC Adv. 2015, 5 , 49623. doi: 10.1039/C5RA07092A

(17) Toyoda, T.; Oshikane, K.; Li, D.; Luo, Y.; Meng, Q.; Shen, Q. Appl. Phys. 2010, 108, 114304. doi: 10.1063/1.3517066

(18) Zhang, Q.; Guo, X.; Huang, X.; Huang, S.; Li, D.; Luo, Y.; Shen, Q.; Toyoda, T.; Meng, Q. Phys. Chem. Chem. Phys. 2011, 13, 4659. doi: $10.1039 / \mathrm{c} 0 \mathrm{cp} 02099 \mathrm{k}$

(19) Lee, Y. L.; Lo, Y. S. Adv. Funct. Mater. 2009, 19, 604. doi: 10.1002/adfm.v19:4

(20) Xu, Y.; Wu, W.; Rao, H.; Chen, H.; Kuang, D.; Su, C. Nano Energy 2015, 11, 621. doi: 10.1016/j.nanoen.2014.11.045

(21) Bai, Y.; Han, C.; Chen, X.; Yu, H.; Zong, X.; Li, Z.; Wang, L. Nano Energy 2015, 13, 609. doi: 10.1016/j.nanoen.2015.04.002

(22) Pan, Z.; Zhang, H.; Cheng, K.; Hou, Y.; Hua, Y.; Zhong, X. ACS Nano 2012, 6, 3982. doi: 10.1021/nn300278z

(23) Sambur, J. B.; Novet, T.; Parkinson, B. A. Science 2010, 330, 63. doi: 10.1126/science. 1191462

(24) Zhang, J.; Cao, J.; Church, C. P.; Miller, E. M.; Luther, J. M.; Klimov, V. I.; Beard, M. C. Nano Lett. 2014, 14, 6010. doi: $10.1021 / \mathrm{n} 1503085 \mathrm{v}$

(25) Semonin, O. E.; Luther, J. M.; Choi, S.; Chen, H. Y.; Gao, J.; Nozik, A. J. N.; Beard, M. C. Science 2011, 334, 1530. doi: 10.1126/science. 1209845

(26) Luther, J. M.; Law, M.; Beard, M. C.; Song, Q.; Reese, M. Q.; Ellingson, R. J.; Nozik, A. J. Nano Lett. 2008, 8, 3488. doi: $10.1021 / \mathrm{nl} 802476 \mathrm{~m}$

(27) Braga, A.; Gimenez, S.; Concina, I.; Vomiero, A.; Mora-Sero, I. J. Phys. Chem. Lett. 2011, 2, 454. doi: 10.1021/jz2000112

(28) González-Pedro, V.; Sima, C.; Marzari, G.; Boix, P. P.; Giménez, S.; Shen, Q.; Dittrich, T.; Mora-Seró, I. Phys. Chem. Chem. Phys. 2013, 15, 13835. doi: 10.1039/c3cp51651b 
(29) Zhou, N.; Chen, G.; Zhang, X.; Cheng, L.; Luo, Y.; Li, D.; Meng, Q. Electrochem. Commun. 2012, 2, 454.

(30) Zhou, N.; Yang, Y.; Huang, X.; Wu, H.; Luo, Y.; Li, D.; Meng, Q. ChemSusChem 2013, 6, 687. doi: 10.1002/cssc.201200763

(31) Lee, J. W.; Son, D. Y.; Ahn, T. K.; Shin, H. W.; Kim, I. Y.; Hwang, S. J.; Ko, M. J.; Sul, S.; Han, H.; Park, N. G. Scientific Reports 2013, 3, 1050.

(32) Zhang, J.; Gao, J.; Church, C. P.; Miller, E. M.; Luther, J. M.; Klimov, V. I.; Beard, M. C. Nano Lett. 2014, 14, 6010. doi: $10.1021 / \mathrm{n} 1503085 \mathrm{v}$

(33) Rhee, J. H.; Chung, C. C.; Diau, E. W. G. NPG Asia Mater 2013, 5 , e68.

(34) Bang, J. H.; Kamat, P. V. ACS Nano 2009, 3, 1467. doi: $10.1021 / \mathrm{nn} 900324 \mathrm{q}$

(35) Yu, P. R.; Zhu, K.; Norman, A. G.; Ferrere, S.; Frank, A. J.; Nozik, A. J. J. Phys. Chem. B 2006, 110, 25451. doi: 10.1021/jp064817b

(36) Laghumavarapu, R. B.; El-Emawy, M.; Nuntawong, N.; Moscho, A.; Lester, L. F.; Huffaker, D. L. Appl. Phys. Lett. 2007, 91, 243115. doi: 10.1063/1.2816904

(37) Guo, X. D.; Ma, B. B.; Wang, L. D.; Gao, R.; Dong, H. P.; Qiu, Y. Acta Phys. -Chim. Sin. 2013, 29, 1240. [ 郭旭东, 马蓓蓓, 王 立铎, 高 瑞, 董豪鹏, 邱 勇. 物理化学学报, 2013, 29, 1240.] doi: 10.3866/PKU.WHXB201303261

(38) Li, T. L.; Lee, Y. L.; Teng, H. Energy Environ. Sci. 2012, 5 , 5315. doi: 10.1039/C1EE02253A

(39) McDaniel, H.; Fuke, N.; Makarov, N. S.; Pietryga, J. M.; Klimov, V. I. Nat. Commun. 2013, 4, 2887.

(40) Bai, B.; Kou, D.; Zhou, W.; Zhou, Z.; Wu, S. Green Chem. 2015, 17, 4377. doi: 10.1039/C5GC01049G

(41) Kim, S.; Kang, M.; Kim, S.; Heo, J. H.; Noh, J. H.; Im, S. H.; Seok, S.; Kim, S. W. ACS Nano 2013, 7, 4756. doi: $10.1021 / \mathrm{nn} 401274 \mathrm{e}$

(42) McDaniel, H.; Fuke, N.; Pietryga, J. M.; Klimov, V. I. J. Phys. Chem. Lett. 2013, 4, 355. doi: 10.1021/jz302067r

(43) Pan, Z.; Zhao, K.; Wang, J.; Zhang, H.; Feng, Y.; Zhong, X. ACS Nano 2013, 7, 5215. doi: 10.1021/nn400947e

(44) Luo, J.; Wei, H.; Li, F.; Huang, Q.; Li, D.; Luo, Y.; Meng, Q. Chem. Commun. 2014, 50, 3464. doi: 10.1039/c3cc49335k

(45) Zhu, D. H.; Zhong, R.; Cao, Y.; Peng, Z. H.; Feng, A. X.; Xiang, W. D.; Zhao, J. L. Acta Phys. -Chim. Sin. 2014, 30, 1861. [朱德华, 钟 蓉, 曹 宇, 彭志辉, 冯爱新, 向卫东, 赵 家龙. 物理化学学报, 2014, 30, 1861.] doi: 10.3866/PKU.WHXB201408044

(46) Li, T. L.; Lee, Y. L.; Teng, H. Energy Environ. Sci. 2012, 5, 5315. doi: 10.1039/C1EE02253A

(47) Pan, Z.; Mora-Sero, I.; Shen, Q.; Zhang, H.; Li, Y.; Zhao, K.; Wang, J.; Zhong, X.; Bisquert, J. J. Am. Chem. Soc. 2014, 136, 9203. doi: 10.1021/ja504310w

(48) Kim, S.; Kang, M.; Kim, S.; Heo, J. H.; Noh, J. H.; Im, S. H.; Seok, S. I.; Kim, S. W. ACS Nano 2013, 7, 4756.
(49) Luo, J.; Wei, H.; Huang, Q.; Hu, X.; Zhao, H.; Yu, R.; Li, D.; Luo, Y.; Meng, Q. Chem. Commun. 2013, 49, 3881.

(50) Jiao, S.; Shen, Q.; Mora-Sero, I.; Wang, J.; Pan, Z.; Zhao, K.; Kuga, Y.; Zhong, X.; Bisquert, J. ACS Nano 2015, 9, 908. doi: 10.1021/nn506638n

(51) Wang, J.; Mora-Sero, I.; Pan, Z.; Zhang, H.; Feng, Y.; Yang, G.; Zhong, X.; Bisquert, J. J. Am. Chem. Soc. 2013, 135, 15913. doi: $10.1021 / \mathrm{ja} 4079804$

(52) Sahasrabudhe, A.; Bhattacharyya, S. Chem. Mater. 2015, 27, 4848. doi: 10.1021/acs.chemmater.5b01731

(53) Itzhakov, S.; Shen, H.; Buhbut, S.; Lin, H.; Oron, D. J. Phys. Chem. C 2013, 117, 22203. doi: 10.1021/jp312190x

(54) Zhang, Q.; Chen, G.; Yang, Y.; Shen, X.; Zhang, Y.; Li, C.; Yu, R.; Luo, Y.; Li, D.; Meng, Q. Phys. Chem. Chem. Phys. 2012, 16,6479 .

(55) Park, J. H.; Kim, D. H.; Shin, S. S.; Han, H. S.; Lee, M. H.; Jung, H. S.; Noh, J. H.; Hong, K. S. Adv. Energy Mater. 2014, 4, 1300395 .

(56) Lin, Y.; Meng, Y.; Tu, Y.; Zhang, X. Opt. Commun. 2015, 346, 64. doi: 10.1016/j.optcom.2015.02.031

(57) Xiao, J.; Huang, Q.; Xu, J.; Li, C.; Chen, G.; Luo, Y.; Li, D.; Meng, Q. J. Phys. Chem. C 2014, 118, 4007. doi: 10.1021/jp411922e

(58) Hossain, M. A.; Jennings, J. R.; Koh, Z. Y.; Wang, Q. ACS Nano 2011, 5, 3172. doi: 10.1021/nn200315b

(59) Hossain, M. A.; Koha, Z. Y.; Wang, Q. Phys. Chem. Chem. Phys. 2012, 14, 7367. doi: 10.1039/c2cp40551b

(60) Tian, J.; Lv, L.; Wang, X.; Fei, C.; Liu, X.; Zhao, Z.; Wang, Y.; Cao, G. J. Phys. Chem. C 2014, 118, 16611. doi: $10.1021 / \mathrm{jp} 412525 \mathrm{k}$

(61) Li, C.; Yang, L.; Xiao, J.; Wu, Y. C.; Sondergaard, M.; Luo, Y.; Li, D.; Meng, Q.; Iversen, B. B. Phys. Chem. Chem. Phys. 2013, 15, 8710. doi: 10.1039/c3cp50365h

(62) Zhu, Z.; Qiu, J.; Yan, K.; Yang, S. ACS Appl. Mater. Interfaces 2013, 5, 4000.

(63) Yan, K.; Zhang, L.; Qiu, J.; Qiu, Y.; Zhu, Z.; Wang, J.; Yang, S. J. Am. Chem. Soc. 2013, 135, 9531. doi: 10.1021/ja403756s

(64) Tian, J.; Lv, L.; Fei, C.; Wang, Y.; Liu, X.; Cao, G. J. Mater. Chem. A 2014, 2, 19653. doi: 10.1039/C4TA04534C

(65) Li, W. J.; Zhong, X. H. J. Phys. Chem. Lett. 2015, 6, 796. doi: 10.1021/acs.jpclett.5b00001

(66) Santra, P. K.; Nair, P. V.; Thomas, K. G.; Kamat, P. V. J. Phys. Chem. Lett. 2013, 4, 722. doi: 10.1021/jz400181m

(67) Yu, X.; Liao, J.; Qiu, K.; Kuang, D.; Su, C. ACS Nano 2011, 5, 9494. doi: 10.1021/nn203375g

(68) Li, W. J.; Zhong, X. H. Acta Phys. Sin. 2015, 64, 038806. [李文 杰, 钟新华. 物理学报, 2015, 64, 038806.]

(69) Hu, X.; Zhang, Q.; Huang, X.; Li, D.; Luo, Y.; Meng, Q. J. Mater. Chem. 2011, 21, 15903. doi: 10.1039/c1jm12629f

(70) Li, W.; Pan, Z.; Zhong, X. J. Mater. Chem. A 2015, 3, 1649. doi: $10.1039 / \mathrm{C} 4 \mathrm{TA} 05134 \mathrm{C}$ 
(71) Yang, J.; Oshima, T.; Yindeesuk, W.; Pan, Z.; Zhong, X.; Shen, Q. J. Mater. Chem. A 2014, 2, 20882. doi: 10.1039/C4TA04353G

(72) Gopi, C. V. V. M.; Venkata-Haritha, M.; Kim, S. K.; Kim, H. J. Nanoscale 2015, 7, 12552. doi: 10.1039/C5NR03291A

(73) Mu, L.; Liu, C.; Jia, J.; Zhou, X.; Lin, Y. J. Mater. Chem. A 2013, 1, 8353. doi: 10.1039/c3ta11780d

(74) Hod, I.; Zaban, A. Langmuir 2014, 30, 7264. doi: 10.1021/la403768j

(75) Roelofs, K. E.; Brennan, T. P.; Dominguez, J. C.; Bailie, C. D.; Margulis, G. Y.; Hoke, E. T.; McGehee, M. D.; Bent, S. F. J. Phys. Chem. C 2013, 117, 5584. doi: 10.1021/jp311846r

(76) Yu, K.; Lin, X.; Lu, G.; Wen, Z.; Yuan, C.; Chen, J. RSC Adv. 2012, 2, 7843. doi: 10.1039/c2ra20979a

(77) Chen, Z.; Peng, W.; Zhang, K.; Zhang, K.; Zhang, J.; Yang, X.; Numata, Y.; Han, L. J. Mater. Chem. A 2014, $2,7004$.

(78) Niu, G.; Li, N.; Wang, L.; Li, W.; Qiu, Y. Phys. Chem. Chem. Phys. 2014, 16, 18327. doi: 10.1039/C4CP02520B

(79) Huang, J.; Yuan, C.; Chen, H.; Sun, J.; Sun, L.; Ågren, H. ACS Appl. Mater. Interfaces 2014, 6, 18808. doi: 10.1021/am504536a

(80) Ning, Z.; Tian, H.; Yuan, C.; Fu, Y.; Sun, L.; Ågren, H. Chem. Eur. J. 2011, 17, 6330. doi: 10.1002/chem.201003527

(81) Li, L.; Yang, X.; Gao, J.; Tian, H.; Zhao, J.; Anders, H.; Sun, L. J. Am. Chem. Soc. 2011, 133, 8450.

(82) Ning, Z.; Yuan, C.; Tian, H.; Fu, Y.; Li, L.; Sun, L.; Ågren, H. J. Mater. Chem. 2012, 22, 6032. doi: 10.1039/c2jm15857d

(83) Shu, T. Chem. Engineer 2013, 4, 42. [舒 婷. 化学工程师, 2013, 4, 42.]

(84) Yu, Z.; Zhang, Q.; Qin, D; Luo, Y; Li, D.; Shen, Q.; Toyoda, T.; Meng, Q. Electrochem. Commun. 2012, 12, 1776.

(85) Wang, S.; Zhang, Q.; Xu, Y.; Li, D.; Luo, Y.; Meng, Q. J. Power Sources 2013, 224, 152. doi: 10.1016/j.jpowsour. 2012.09.044

(86) Yang, Y.; Wang, W. J. Power Sources 2015, 285, 70.

(87) Liu, L.; Liu, C.; Fu, W.; Deng, L.; Zhong, H. ChemPhysChem doi: $10.1002 /$ cphc. 201500627
(88) Yang, Y.; Zhu, L.; Sun, H.; Huang, X.; Luo, Y.; Li, D.; Meng, Q. ACS Appl. Mater. Interfaces 2012, 4, 6162. doi: 10.1021/am301787q

(89) Yang, Z.; Chen, C. Y.; Liu, C. W.; Chang, H. T. Chem. Commun. 2010, 46, 5485. doi: 10.1039/c0cc00642d

(90) Punnoose, D.; Kim, H. J.; Rao, S. S.; Kumar, CH. S. S. P. J. Elecreoanal. Chem. 2015, 750, 19. doi: 10.1016/j.jelechem.2015.05.003

(91) Kim, H. J.; Kim, D. J.; Rao, S. S.; Savariraj, A. D.; SooKyoung, K.; Son, M. K.; Gopi, C. V. V. M.; Prabakar, K. Electrochim. Acta 2014, 127, 427. doi: 10.1016/j.electacta.2014.02.019

(92) Gopi, C. V. V. M.; Rao, S. S.; Soo-Kyoung, K.; Punnoose, D.; Kim, H. J. J. Power Sources 2015, 275, 547. doi: 10.1016/j.jpowsour.2014.11.038

(93) Zhang, X.; Huang, X.; Yang, Y.; Wang, S.; Gong, Y.; Luo, Y.; Li, D.; Meng, Q. ACS Appl. Mater. Interfaces 2013, 5, 5954. doi: $10.1021 / \mathrm{am} 400268 \mathrm{j}$

(94) Deng, M.; Huang, S.; Zhang, Q.; Li, D.; Luo, Y.; Meng, Q. Chem. Lett. 2010, 39, 1168. doi: 10.1246/cl.2010.1168

(95) Yang, Y.; Zhu, L.; Sun, H.; Huang, X.; Luo, Y.; Li, D.; Meng, Q. ACS Appl. Mater. Interfaces 2012, 4, 6162. doi: $10.1021 / \mathrm{am} 301787 \mathrm{q}$

(96) Li, D.; Cheng, L.; Zhang, Y.; Zhang, Q.; Huang, X.; Luo, Y.; Meng, Q. Sol. Energy Mater. Sol. Cells 2014, 120, 454. doi: 10.1016/j.solmat.2013.09.025

(97) Kim, H. J.; Myung-Sik, L.; Gopi, C. V. V. M.; Venkata-Haritha, M.; Rao, S. S.; Kim, S. K. Dalton Trans. 2015, 44, 11340. doi: 10.1039/C5DT01412C

(98) Sung, S. D.; Lim, I.; Kang, P.; Lee, C.; Lee, W. I. Chem. Commun. 2013, 49, 6054. doi: 10.1039/c3cc40754c

(99) Radich, J. G.; Dwyer, R.; Kamat, P. V. J. Phys. Chem. Lett. 2011, 2, 2453. doi: 10.1021/jz201064k

(100) Seol, M.; Youn, D. H.; Kim, J. Y.; Jang, J. W.; Choi, M.; Lee, J. S.; Yong, K. Adv. Energy Mater. 2014, 4, 1300775.

(101) Choi, H. M.; Ji, I. A.; Bang, J. H. ACS Appl. Mater. Interfaces 2014, 6, 2335. doi: 10.1021/am404355m 